\author{
Abstracta Iranica \\ Abstracta Iranica Revue bibliographique pour le domaine irano-aryen \\ Volume 37-38-39 | 2018 \\ Comptes rendus des publications de 2014-2016
}

\title{
Michael Philip Penn. Envisioning Islam. Syriac Christians and the Early Muslim World
}

\section{Florence Jullien}

\section{(2) OpenEdition}

\section{Journals}

Édition électronique

URL : http://journals.openedition.org/abstractairanica/45219

DOI : 10.4000/abstractairanica.45219

ISBN : 1961-960X

ISSN : 1961-960X

Éditeur :

CNRS (UMR 7528 Mondes iraniens et indiens), Éditions de l'IFRI

Référence électronique

Florence Jullien, « Michael Philip Penn. Envisioning Islam. Syriac Christians and the Early Muslim World», Abstracta Iranica [En ligne], Volume 37-38-39 | 2018, document 38, mis en ligne le 30 décembre 2018, consulté le 26 septembre 2020. URL : http://journals.openedition.org/abstractairanica/45219 ; DOI : https://doi.org/10.4000/abstractairanica.45219

Ce document a été généré automatiquement le 26 septembre 2020.

Tous droits réservés 


\title{
Michael Philip Penn. Envisioning Islam. Syriac Christians and the Early Muslim World
}

\author{
Florence Jullien
}

\section{RÉFÉRENCE}

Michael Philip Penn. Envisioning Islam. Syriac Christians and the Early Muslim World. Philadelphie: University of Pennsylvania Press, 2015, 304 p. ISBN 9780812247220 , (Divinations: Rereading Late Ancient Religion)

1 Dans le sillage de travaux pionniers en la matière, et spécialement les études de Patricia Crone ou de Robert Hoyland, cet ouvrage met l'accent sur l'importance des sources syriaques pour reconstruire une histoire des premiers siècles de l'islam au regard de sources extérieures, non arabes et non musulmanes. L'A. reconsidère cette documentation sur la période des $\mathrm{VII}^{\mathrm{e}} \mathrm{IX}^{\mathrm{e}}$ siècles, qui a l'avantage d'être contemporaine et très variée: sources épistolaires et correspondances, traités théologiques ou ascétiques, ouvrages d'ordre scientifique ou canonique, historiographies, etc. Le décryptage des différentes lectures et interprétations données par les auteurs chrétiens, et de leurs perceptions souvent subjectives du passé, ouvre la voie à une analyse critique, historique et littéraire, des événements rapportés, ainsi reconstruits et même déconstruits. Cette enquête remet en situation le contexte socio-culturel de l'arrivée de l'islam et plus particulièrement le développement des relations islamochrétiennes; elle rend compte aussi des diverses représentations des musulmans dans les textes syriaques et leurs transformations au cours du temps.

2 L'ouvrage est partagé en quatre chapitres, augmentés d'une introduction et d'une conclusion concises. Le premier (p. 15-52) présente les sources syriaques relatives à la conquête arabe; l'appréhension de l'événement fut différente selon les choix christologiques des différentes communautés chrétiennes (dyophysite, miaphysite ou 
chalcédonienne). Les sources, spécialement historiographiques, s'en font l'écho. Ce n'est que progressivement que les nouveaux maîtres du sol musulman furent associés aux malheurs du temps. L'arrivée de populations jugées infidèles fut d'abord perçue comme l'instrument de la volonté divine contre le péché du peuple chrétien (chez l'écrivain syro-oriental Jean bar Penkāyē par exemple, à la fin du VII ${ }^{e}$ siècle). Avec le mouvement d'islamisation de la société qui commença sous le gouvernement du calife 'Abd al-Malik b. Marwān (m. en 705), les littérateurs syriaques proposèrent une interprétation à la fois spiritualisée et politique de ces événements, en produisant des ouvrages à teneur apocalyptique éminemment illustrés par l'Apocalypse du PseudoMéthode qui dépeint les succès militaires des musulmans tout en décrivant la venue espérée d'un personnage providentiel, appelé le «Dernier Empereur », qui viendrait mettre fin à cette conquête et instaurer un règne fondé sur les valeurs chrétiennes. Dans le deuxième chapitre (p. 53-101), l'A. s'intéresse aux différentes dénominations attribuées aux chrétiens par les premiers musulmans, et s'interroge sur leur signification qui, selon lui, sont porteuses aussi d'une nouvelle compréhension de l'islam par les communautés chrétiennes. Le troisième chapitre (p. 102-141) fonctionne comme une "galerie de portraits" et propose d'identifier les autorités de l'islam et des gouvernants musulmans derrière les différentes présentations réalisées par les auteurs syriaques. Ces descriptions sont aussi prétextes à des controverses et des traités polémiques pour les écrivains syriaques qui développent des argumentations théologiques contre la doctrine conspuée. Le dernier chapitre (p. 142-182) exploite le vaste corpus des textes syriaques pour déceler les échanges religieux et culturels qui se sont mis en place entre $\mathrm{VII}^{\mathrm{e}}$ et $\mathrm{IX}^{\mathrm{e}}$ siècle, dans leur complexité et leurs évolutions. La diffusion de l'islam au sein des sociétés plurielles de la Mésopotamie, de la Babylonie, et de la Perse a eu un profond impact sur les relations islamo-chrétiennes, affectant parfois l'identité même des communautés chrétiennes, générant de nouvelles pratiques par les fréquentations de fêtes musulmanes ou l'adoption de rites par exemple, voire une nouvelle expression de la foi par la négation de la divinité du Christ.

En fonction des critères éditoriaux de la collection, les notes ont été reportées en fin d'ouvrage (p. 187-250), ce qui ne facilite pas toujours la lecture. L'ensemble se termine par une bibliographie répartie en deux rubriques: les sources syriaques sur l'islam et les études secondaires (curieusement dénommées "sources non syriaques»!), et un utile index. Souhaitons que cet ouvrage puisse ouvrir la voie à de futures recherches sur cette période de transition, également à travers un élargissement à la documentation chrétienne orientale caucasienne ou arabe chrétienne produite en territoire musulman. Il constitue une importante avancée pour renouveler l'histoire des relations islamo-chrétiennes durant les premiers siècles de l'islam.

\section{AUTEURS}

\section{FLORENCE JULLIEN}

CNRS, Mondes iranien et indien, Paris 